\title{
化学“情思” 课堂的生态意蕴与构建
}

\author{
刘李治 \\ 江苏省海门中学附属学校 \\ DOI:10.32629/jief.v2i5.1422
}

[摘 要] 化学教学要在人类文化背景下构建化学课程体系, 充分体现化学课程的人文内涵, 发挥化学课程对培养学生人文精神的积极作用。 本文提出了化学 “情思” 课堂生态应充盈着积极向上的生活气息, 彰显、尊重和理解学生个性的独特发展的意蕴, 结合教学实践从平等、交 流和融入的角度阐述了构建化学 “情思”课堂生态的策略

[关键词] 化学 “情思”课堂; 生态; 生活气息; 个性发展; 心灵

中图分类号: G633.8 文献标识码: A

化学教学要在人类文化背景下构建化学课程体系, 充分体现化学课 程的人文内涵, 发挥化学课程对培养学生人文精神的积极作用。因此, 化学学科的教学只有充分认识化学课程的人文性、生命性和复杂性, 才 能建构起 “强大、丰富、共生的 “独一整体”, 才能形成关注情境、情 商、情感、思辨、思维、思想, 追求 “情思碰撞, 情思激荡, 情思相融” 的 “情思” 课堂生态, 才能让课堂尊重个体差异, 彰显人性魅力和生活 气息, 充满科学理性和生命关切。因此, 化学 “情思” 课堂的生态应该 是师生互动、心灵对话、砥研成长的 “一方池塘”, 是激发潜能、张扬个 性、展现学生自我魅力的 “一团火焰”, 是师生人生旅程中一段重要的生 命经历。

\section{1 化学 “情思” 课堂生态应充盈着积极向上的生活气息}

杜威说过: “生活即教育”。斯宾塞提到 “教育是为了完满的生活”。 化学课堂要结合学生已有的经验和将要经历的社会生活实际, 引导学生 关注人类面临的与化学相关的社会问题, 培养学生的社会责任感、参与 意识和决策能力。” 因此, 化学 “情思” 课堂生态要努力为学生核心素养 的发展搭建沟通科学理性与生活实践的桥梁, 还课堂教学以生活本色, 使学生在与生活世界的联系、沟通、体悟、理解与认同中感受到生命的 崇高, 学会生存, 促进个性发展。例如, 在进行元素及其化合物相关内 容的教学时, 要从元素及其化合物在生产生活中的实际应用创设真实的 有意义的学习情境; 在进行化学基本概念和基本原理的教学时, 不仅要 让学生理解概念和原理, 而且要发展学生应用基本概念和化学基本原理 解决生产生活中的问题, 让学生真正感受到化学是一门中心的、实用的 和创造性的科学, 能形成对化学学科价值的认同, 消除对化学的误解与 疏离, 形成正确的价值观和世界观。 发展

2 化学 “情思” 课堂生态应彰显、尊重和理解学生个性的独特

人本主义教学观认为: 学生是有思想、有感情、有独立人格的个体, 是有主观能动性的个体, 是不断发展和进步的个体。教育以育人为根本, 教育的原点就是让学生成为一个真正意义上的完整的人, 同时也是最本 质和最高的价值与目标。然而, 当下的化学课堂由于受各种因素的影响, 过分追求高效和高分, 学生主体只是公开课上的 “县花”, 学生的个性发 展被无形抹杀、遮蔽。新课程背景下的化学课堂生态要强调传授知识、 启迪智慧、点化或润泽生命的融合, 彰显、尊重和理解学生个性的独特 发展。

2.1 化学 “情思” 课堂生态系统中学生必须是第一要素, 平等是促 进个性发展的基本前提

学生是具有独立意义、独一无二、有生命尊严的个体。每一个学生 的想法和头脑中的表象都相互碰撞、呼应起来的 “交响乐” 的本身, 乃 是教学的最大妙趣所在。教师化学课堂生态系统中平等的首席, 学生却 是第一要素, 通过平等地对话、交流与评价, 会让学生的人格跟健全,
真真实实地享受到生命的尊严。站在教育的神坛, 高高在上, 目中无人, 只会让师生间产生隔阂与冷漠, 谈不上回归学生的现实生活, 珍惜和尊 重个体差异, 不可能做到为学生的未来生存和发展奠基。因此, 化学 “情 思” 课堂生态应致力于学生独特个性的发展, 应从多元智能的视角, 密 切关注学生心理和情绪的变化, 关心学生的学习生活需要和困惑, 努力 让学生从应试教育的桎梏和羁绊中彻底解放出来。

2.2 化学 “情思” 课堂生态应努力践行自主、合作与探究, 交流是 促进个性发展的通行证

自主就是给学生学习的自主权, 是以学生为中心的体现, 是对学生 个体差异的尊重, 是学生核心素养发展的关键。合作包括生生之间、师 生之间、小组与小组之间的合作。合作学习可以让学生在合作中学会倾 听, 取他人之长补已之短, 学会宽容和沟通, 学会协作、分享和表达。 探究不仅是学生学习化学的基本方法, 而且是教师培养学生创造精神的 重要途径。“限时讲授、合作学习、踊跃展示” 三点基本要求是对课堂生 态最好的诠释。

例如, 在进行 $\mathrm{Fe} 2+$ 和 $\mathrm{Fe} 3+$ 的相互转化的教学时, 首先要求学生从氧 化还原的视角自主分析相互转化的本质, 寻找相应的试剂, 设计实验方 案, 小组交流, 完善方案, 小组合作与小心求证, 展示交流, 最后归纳 总结解决问题的一般思路。这样的化学课堂生态, 学生在活动中充分自 主, 真情投入; 教师认真倾听, 抓住关键时机进行适时指导。师生互动 合作、心灵对话, 在对话中生成, 在生成中引导, 在引导中感悟。这样 的化学课堂生态时刻闪耀着师生个体知识经验、智慧、情感、态度、价 值观与教学目标之间的互相交汇碰撞的火花, 彼此经历了曲径通幽、柳 暗花明, 解决困惑与收获成功与惊喜的探究体验, 充满鲜活的人性。

2.3 化学 “情思” 课堂生态要充满发现的喜悦和爱的交融, 融入是 促进个性发展的关键环节

化学 “情思” 课堂是师生双方共同经历的一段发现之旅, 彼此行板 如歌, 认知和思维的触角不断深入, 情感不断碰撞、变化、共鸣和升华, 所以融入是促进学生个性发展的关键环节, 课堂教学中通过共同分享发 现的喜悦, 达到爱的交融与升华, 为学生实现个性发展的目标打开了关 键的一步。师生在融入过程中形成的 “零距离”, 使学生亲近、信任教师, 教师给知识注入生命, 知识因此而鲜活; 给生命融入知识, 生命因此而 厚重。

\section{[参考文献]}

[1]高颖端. 以问题为中心激活高中化学课堂 [J]. 数理化解题研 究,2020(24):74-75.

[2]葛许䧻. 高中化学高效课堂的构建策略研究 [J]. 数理化解题研 究,2020(24):76-77.

[3] 肖轶. 浅析初中化学教学有效性 [J]. 数理化解题研 究,2020(23):103-104. 